\title{
Hemodialysis with end-stage renal disease did not raise the risk of intracranial hemorrhage after a head injury
}

Hsin-Hung Chen ${ }^{1}$, Chien-Chin Hsu' ${ }^{1,2}$, Shih-Feng Weng ${ }^{3}$, Hung-Jung Lin 1,2,4, Jhi-Joung Wang ${ }^{5}$, How-Ran Guo 6,7, Shih-Bin Su ${ }^{8,9,10}$, Chien-Cheng Huang ${ }^{1,6,8,11,12^{*}}$ and Jiann-Hwa Chen ${ }^{13,14^{*}}$

\begin{abstract}
Background: Hemodialysis (HD) treatment for end-stage renal disease (ESRD) (HD ${ }^{+E S R D}$ ) may increase the risk of intracranial hemorrhage $(\mathrm{ICH})$ after a head injury $(\mathrm{HI})$ for which heparin is used. However, the results of noncontrast head computed tomography $(\mathrm{CT})$ in such patients are not always clear. We aimed to evaluate the effect of HD on the risk of $\mathrm{ICH}$ in ESRD patients and in controls without ESRD with $\mathrm{HD}\left(\mathrm{HD}^{-\mathrm{ESRD}}\right)$, and to determine whether to lower the threshold of head $\mathrm{CT}$ in $\mathrm{HD}^{+E S R D}$ patients after $\mathrm{HI}$.
\end{abstract}

Methods: In this nationwide population-based study using Taiwan's National Health Insurance Research Database, we enrolled 6938 HD $^{+E S R D}$ HI patients for the case group and 13,876 randomly selected HD ${ }^{-E S R D}$ HI patients for the control group. Measures of the post-HI association between $\mathrm{HD}^{+E S R D}$ and ICH determined using conditional logistic regression.

Results: Five hundred sixty-eight (2.74 \%) patients had post-HI ICH: 185 in the HDESRD group (2.67 \% of cases) and 383 were from the HD ${ }^{-E S R D}$ group (2.76 \% of controls). Conditional logistic regression analysis revealed that after adjusting for age, gender, diabetes, hypertension, congestive heart failure, stroke, cancer, and liver disease, HD ${ }^{+E S R D}$ patients had no higher odds of ICH (adjusted odds ratio [AOR]: 0.91; $95 \%$ confidence interval [CI]: 0.75-1.11) than did $H D^{-E S R D}$ patients. In the subgroup analysis of immediate $I C H, H D^{+E S R D}$ patients had lower odds than did $H^{-E S R D}$ patients (AOR: $0.73 ; 95 \% \mathrm{Cl}$ : 0.56-0.94).

Conclusions: $\mathrm{HD}^{+\mathrm{ESRD}}$ did not increase the post-HI risk of $\mathrm{ICH}$. Therefore, it may not be necessary to lower the threshold of head $C T$ in $\mathrm{HD}^{+\mathrm{ESRD}}$ patients.

Keywords: End-stage renal disease, Head CT, Head injury, Hemodialysis, Intracranial hemorrhage

\section{Introduction}

The population of patients with end-stage renal disease (ESRD) who require dialysis is progressively growing, and the mortality rate of this group is much higher than that of the general population in the U.S.[1]. In 2009, 116,395 patients started therapy for ESRD, and the prevalent population reached 571,414, including 398,861 dialysis patients [1]. The incident rate increased $1.1 \%$, to

\footnotetext{
*Correspondence: chienchenghuang@yahoo.com.tw; chenjiannhwa@yahoo. com.tw

'Department of Emergency Medicine, Chi-Mei Medical Center, 901

Zhonghua Road, Yongkang District, Tainan City 710, Taiwan

${ }^{13}$ Department of Emergency Medicine, Cathay General Hospital, No. 280, Sec. 4, Ren'ai Road, Da'an District, Taipei City 106, Taiwan
}

Full list of author information is available at the end of the article
355.4 per million, and total expenditures reached $\$ 42.5$ billion [1]. In Taiwan, the number of ESRD patients who require hemodialysis (HD) has also increased considerably over the past two decades [2]. Taiwan has had the greatest incidence of ESRD since 2000, according to an international comparison based on data from the U.S. Renal Data System [3].

Head injury (HI) often results in lifelong physical, cognitive, behavioral, and social dysfunction for patients who, in turn, may place major social and financial burdens on their families and society $[4,5]$. It is estimated that, in the U.S., around 5.3 million people are living with a HI-related disability [6], and in the E.U., approximately 7.7 million people who have experienced $\mathrm{HI}$ have 
disabilities [7]. There has been a shift toward older patients with $\mathrm{HI}$ for whom falls are the primary cause of $\mathrm{HI}$ among the elderly, resulting in more contusion injuries [8]. The high incidence of comorbidities and the frequent use of platelet aggregation inhibitors and oral anticoagulants among older patients have a negative influence on outcome after HI [8].

The widespread availability of head computed tomography $(\mathrm{CT})$ has greatly helped physicians to better manage patients with HI [9]. Head CT is considered mandatory for all HI patients with an initial or persistent altered level of consciousness [9]. The role of the head $\mathrm{CT}$ in a patient with mild $\mathrm{HI}$ and a normal level of consciousness remains controversial [9]. In the New Orleans [10] and Canadian CT Clinical Decision Rules [11], head $\mathrm{CT}$ is indicated in patients with "known coagulopathy" who are on chronic anticoagulant therapy or are alcohol dependent; however, coagulopathy is potentially a significant risk factor for traumatic intracranial hemorrhage (ICH). HD and continuous renal replacement therapies require extracorporeal blood flow. Some type of anticoagulant, usually heparin or warfarin, is required to prevent thrombosis. However, there is no agreement about how heparin affects with $\mathrm{HD}^{+\mathrm{ESRD}}$ patients with HI. We analyzed a population-based cohort taken from Taiwan's National Health Insurance Research Database (NHIRD) to determine the risk of $\mathrm{ICH}$ after $\mathrm{HI}$ in HD + ESRD patients. We hypothesized that $\mathrm{HD}^{+\mathrm{ESRD}}$ increase the risk for ICH in patients with $\mathrm{HI}$.

\section{Methods}

\section{Data sources}

Taiwan's universal National Health Insurance (NHI) Program covers nearly $100 \%$ of the country's population [12]. The National Health Insurance Research Database (NHIRD), one of the largest and most complete population-based healthcare datasets in the world, contains encrypted patient identification numbers, ICD-9-CM codes for basic sociodemographic information, procedures, diagnoses, prescribed drugs, and dates of discharge and admission [13]. All the expenses of ESRD, HD, HI, and ICH are covered by NHI.

\section{Ethics statement}

This study was conducted according to the Declaration of Helsinki. The Institutional Review Board at Chi-Mei Medical Center approved this study (IRB approved number 10404-E2) and waived the need for informed consents from the patients because the data in this study consists of unidentifiable, national, secondary data released to the public for research. The rights and welfare of the patients are not affected adversely by the waiver.

\section{Selection of cases and controls}

This longitudinal study selected, for the case group, all ESRD patients on maintenance $\mathrm{HD}\left(\mathrm{HD}^{+\mathrm{ESRD}}\right)$ with new-onset HI (ICD-9 codes: 850 [Concussion], 852 [Subarachnoid, subdural and extradural haemorrhage, following injury], 853 [Other and unspecified intracranial hemorrhage following injury], 854 [Intracranial injury of other and unspecified nature], 959.0 [Injury to head, face and neck], 959.01 [Head injury, unspecified], 959.09 [Injury of face and neck]) between 2002 and 2008 (Fig. 1). Their ESRD diagnoses were confirmed if the database indicated that they had a catastrophic illness certificate with the ICD-9 code number 585 for chronic kidney disease.

We also selected two matched controls per case from the Longitudinal Health Insurance Database 2000 (LHID2000), a data subset of the NHIRD that contains claims data for one million beneficiaries randomly selected from the full NHIRD in 2000. There are no significant differences in age, gender, and healthcare costs between the LHID2000 sample group and all NHI enrollees (Fig. 1). The definition of controls was patients who did not have ESRD with HD (HD $\left.{ }^{-\mathrm{ESRD}}\right)$. Controls $\left(\mathrm{HD}^{-\mathrm{ESRD}}\right)$ were matched with cases by age, gender, and index year. Patients diagnosed with ESRD were excluded. As with the cases, we assigned the first use of medical care during the index year as the index date for controls.

We linked to the diagnostic codes through the ambulatory and inpatient care claims databases of the NHI. Baseline comorbidities affecting ICH that may have presented before the index date were diabetes mellitus (DM) (ICD-9 code 250), hypertension (HTN) (ICD-9 codes 401-405), congestive heart failure (CHF) (ICD-9 codes 428), stroke (ICD-9 codes 430-438), cancer (ICD-9 codes 140-208), and liver disease (ICD-9 codes 571.2, 571.4, 571.5, 571.6, 456.0-456.2, 572.2-572.8). We counted these comorbid conditions if they occurred either in the inpatient setting or in 3 or more ambulatory care claims coded 12 months before the index medical care date.

\section{Exposure assessment}

This study compared the risk of ICH between cases and controls. In this study, we identified ICH that included medical codes for (i) immediate ICH after HI (ICD-9 codes: $852,853,854$ ); and (ii) delayed ICH within 7 days of HI (ICD-9 codes: 852, 853, 854, 430 [Subarachnoid hemorrhage], 431 [Intracerebral hemorrhage], 432 [Other and unspecified intracranial hemorrhage], 432.1 [Subdural hemorrhage], 432.9 [Unspecified intracranial hemorrhage]). By definition, all patients had not been previously diagnosed with $\mathrm{ICH}$. 

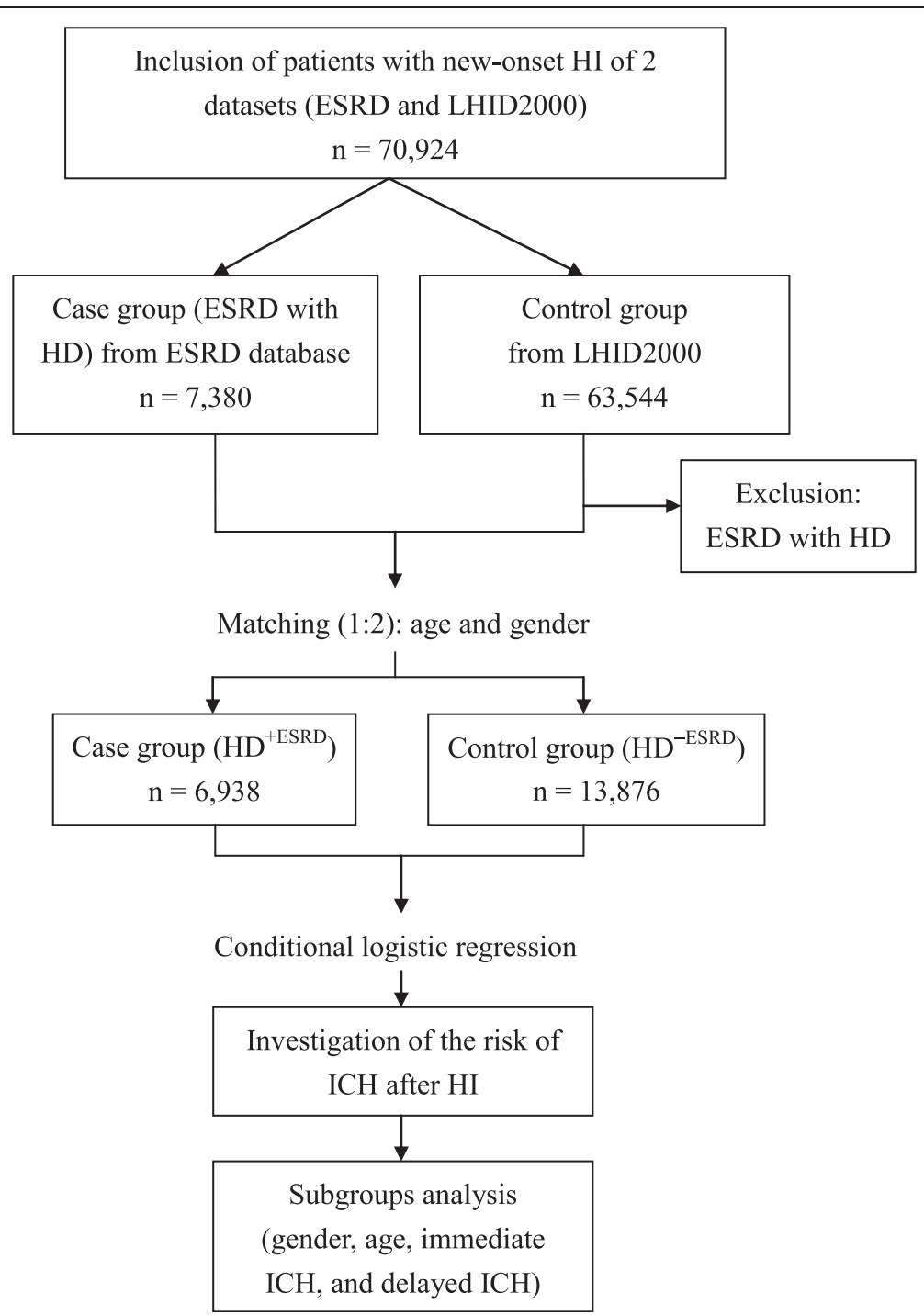

Fig. 1 Flow chart of the study. HI, head injury; ESRD, end-stage renal disease; LHID2000, Longitudinal Health Insurance Database 2000; HD, hemodialysis; ICH, intracranial hemorrhage

\section{Subgroup analysis}

We analyzed the effect of $\mathrm{HD}^{+\mathrm{ESRD}}$ for $\mathrm{ICH}$ in $\mathrm{HI}$ patients in the subgroups based on gender, age, immediate $\mathrm{ICH}$, and delayed ICH. Elderly was defined as $\geq 65$ years old (Table 2).

\section{Statistical analysis}

The significance of the differences in baseline characteristics and comorbid variables between the two groups was evaluated using Pearson $\chi^{2}$ tests for categorical variables and Student's $t$ test for continuous variables. We used conditional logistic regression (based on age, gender, and index year) to examine the association of ESRD with HD and ICH after $\mathrm{HI}$ after the potential confounders of DM, HTN, CHF, stroke, cancer, and liver disease, measured before the index date, had been adjusted for. SAS 9.3.1 for Windows (SAS Institute, Cary, NC, USA) was used for all analyses. Significance was set at $P<0.05$.

\section{Results}

Demographic data of total patients with $\mathrm{HI}$

Between 2002 and 2008, we recruited 6938 patients with $\mathrm{HD}^{+\mathrm{ESRD}}$ and 13,876 age- and gender-matched controls, after ineligible patients had been excluded (Fig. 1; Table 1). The mean ages in the case and control groups on the HI date were identical: $65.52 \pm 12.96$ years old (Table 1). All patients were subclassified into 2 age groups: $0-64$ years old and $\geq 65$ years old (Table 1 ). Pearson $\chi^{2}$ tests revealed a significant difference between the distribution of the comorbidities of DM, HTN, CHF, 
Table 1 Demographic characteristics of patients with head injury

\begin{tabular}{llll}
\hline Characteristic & Cases $\left(\mathrm{HD}^{+ \text {ESRD }}\right)$ & Controls $\left(\mathrm{HD}^{- \text {ESRD }}\right)$ & $P$ \\
\hline Number of patients & 6938 & 13,876 & \\
Age (years) & $65.52 \pm 12.96$ & $65.52 \pm 12.96$ & 0.9978 \\
$0-64$ & $3004(43.30)$ & $6008(43.30)$ & $>0.999$ \\
$\geq 65$ & $3934(56.70)$ & $7868(56.70)$ & \\
Gender & & & \\
Male & $3040(43.82)$ & $6080(43.82)$ & $>0.999$ \\
Female & $3898(56.18)$ & $7796(56.18)$ & \\
Comorbidities & & & $<0.0001$ \\
DM & $3009(43.37)$ & $2538(18.29)$ & $<0.0001$ \\
HTN & $4056(58.46)$ & $5051(36.40)$ & $<0.0001$ \\
CHF & $1035(14.92)$ & $485(3.50)$ & $<0.0001$ \\
Stroke & $1276(18.39)$ & $1743(12.56)$ & $<0.0001$ \\
Cancer & $516(7.44)$ & $540(3.89)$ & $<0.0001$ \\
Liver disease & $727(10.48)$ & $939(6.77)$ & \\
\hline
\end{tabular}

Data are presented as $\mathrm{n}(\%)$ or means \pm standard deviation. ESRD end-stage renal disease, $H D$ hemodialysis, DM diabetes mellitus, HTN hypertension, CHF congestive heart failure

stroke, cancer, and liver disease in cases and controls after matching (Table 1).

\section{Risk of ICH after HI}

Of the $6938 \mathrm{HD}^{+\mathrm{ESRD}}$ patients, 185 (2.67 \%) had $\mathrm{ICH}$ after HI during the follow-up period (Table 2). In the
HD $^{-\mathrm{ESRD}}$ group, 383 of 13,876 patients (2.76 \%) had ICH after HI during the follow-up period (Table 2). The crude OR was 0.97 (95\% CI: 0.81-1.15). After adjusting for patient age, gender, and comorbidities, $\mathrm{HD}^{+\mathrm{ESRD}}$ was not associated with an increased risk of $\mathrm{ICH}$ after $\mathrm{HI}$ compared with the control group (AOR: 0.91; $95 \% \mathrm{CI}$ : 0.75-1.11) (Table 2).

\section{Subgroup analysis}

When patients were categorized by gender and age, the difference in the risk of $\mathrm{ICH}$ between 2 subgroups was not significant (Table 2). In an analysis of immediate and delayed $\mathrm{ICH}, \mathrm{HD}^{+\mathrm{ESRD}}$ patients had a lower risk than did HD ${ }^{-E S R D}$ patients (AOR: 0.73; $95 \%$ CI: 0.56-0.94), especially in the females (AOR: 0.61 ; $95 \%$ CI: $0.43-0.87$ ) and those $\geq 65$ years old (AOR: 0.70 ; $95 \%$ CI: $0.50-0.97$ ) (Table 3). In the delayed ICH analysis, there was no difference between $\mathrm{HD}^{+\mathrm{ESRD}}$ and $\mathrm{HD}^{-\mathrm{ESRD}}$ patients (Table 4).

\section{Discussion}

Using a nationwide population-based study design with a large sample, we found that ESRD with HD did not increase the risk of $\mathrm{ICH}$ after $\mathrm{HI}$, regardless of age or gender. Moreover, $\mathrm{HD}^{+\mathrm{ESRD}}$ patients had a lower risk of immediate ICH. To the best of our knowledge, this is the first study to report the associations between $\mathrm{HD}^{+\mathrm{ESRD}}$ and the risk of ICH after HI. Our findings suggest that it may not be necessary for physicians to lower

Table 2 Comparison of the risk of intracranial hemorrhage after head injury between Case $\left(H D^{+E S R D}\right)$ and Control $\left(H D^{-E S R D}\right)$ groups

\begin{tabular}{|c|c|c|c|c|c|c|}
\hline Outcome & Cases & Controls & Crude OR & $P$ & $A O R$ & $P$ \\
\hline \multicolumn{7}{|l|}{ Overall } \\
\hline Yes, n (\%) & $185(2.67)$ & $383(2.76)$ & $0.97(0.81-1.15)$ & 0.6961 & $0.90(0.74-1.10)$ & 0.3012 \\
\hline No, n (\%) & $6753(97.33)$ & $13,493(97.24)$ & 1.00 & & 1.00 & \\
\hline \multicolumn{7}{|l|}{ Gender } \\
\hline \multicolumn{7}{|l|}{ Male } \\
\hline Yes, n (\%) & 93 (3.06) & $170(2.80)$ & $1.10(0.85-1.42)$ & 0.4788 & $1.03(0.76-1.40)$ & 0.8448 \\
\hline No, n (\%) & $2947(96.94)$ & $5910(97.20)$ & 1.00 & & 1.00 & \\
\hline \multicolumn{7}{|l|}{ Female } \\
\hline Yes, n (\%) & $92(2.36)$ & $213(2.73)$ & $0.86(0.67-1.10)$ & 0.2361 & $0.78(0.59-1.03)$ & 0.0826 \\
\hline No, n (\%) & $3806(97.64)$ & 7583 (97.27) & 1.00 & & 1.00 & \\
\hline \multicolumn{7}{|l|}{ Age (years) } \\
\hline \multicolumn{7}{|l|}{$0<65$} \\
\hline Yes, n (\%) & $84(2.80)$ & $157(2.61)$ & $1.07(0.82-1.40)$ & 0.6112 & $1.01(0.72-1.42)$ & 0.9587 \\
\hline No, n (\%) & $2920(97.20)$ & 5851 (97.39) & 1.00 & & 1.00 & \\
\hline \multicolumn{7}{|l|}{$\geq 65$} \\
\hline Yes, n (\%) & $101(2.57)$ & $226(2.87)$ & $0.89(0.70-1.13)$ & 0.3430 & $0.83(0.64-1.08)$ & 0.1596 \\
\hline No, n (\%) & $3833(97.43)$ & 7642 (97.13) & 1.00 & & 1.00 & \\
\hline
\end{tabular}


Table 3 Comparison of the risk of immediate intracranial hemorrhage after head injury between Case $\left(\mathrm{HD}^{+\mathrm{ESRD}}\right)$ and Control $\left(\mathrm{HD}^{-\mathrm{ESRD}}\right)$ groups

\begin{tabular}{|c|c|c|c|c|c|c|}
\hline Outcome & Case & Control & Crude OR & $P$ & $A O R$ & $P$ \\
\hline \multicolumn{7}{|l|}{ Overall } \\
\hline Yes, n (\%) & $107(1.54)$ & $275(1.98)$ & $0.78(0.62-0.97)$ & 0.0263 & $0.73(0.56-0.94)$ & 0.0166 \\
\hline No, n (\%) & $6831(98.46)$ & $13,601(98.02)$ & 1.00 & & 1.00 & \\
\hline \multicolumn{7}{|l|}{ Gender } \\
\hline \multicolumn{7}{|l|}{ Male } \\
\hline Yes, n (\%) & $56(1.84)$ & $118(1.94)$ & $0.95(0.69-1.31)$ & 0.7449 & $0.85(0.57-1.28)$ & 0.4420 \\
\hline No, n (\%) & 2984 (98.16) & 5962 (98.06) & 1.00 & & 1.00 & \\
\hline \multicolumn{7}{|l|}{ Female } \\
\hline Yes, n (\%) & $51(1.31)$ & $157(2.01)$ & $0.65(0.47-0.89)$ & 0.0070 & $0.61(0.43-0.87)$ & 0.0064 \\
\hline No, n (\%) & 3847 (98.69) & 7639 (97.99) & 1.00 & & 1.00 & \\
\hline \multicolumn{7}{|l|}{ Age (years) } \\
\hline \multicolumn{7}{|l|}{$0<65$} \\
\hline Yes, n (\%) & $46(1.53)$ & $116(1.93)$ & $0.79(0.56-1.11)$ & 0.1780 & $0.79(0.51-1.22)$ & 0.2860 \\
\hline No, n (\%) & $2958(98.47)$ & $5892(98.07)$ & 1.00 & & 1.00 & \\
\hline \multicolumn{7}{|l|}{$\geq 65$} \\
\hline Yes, n (\%) & $61(1.55)$ & $159(2.02)$ & $0.77(0.57-1.03)$ & 0.0766 & $0.70(0.50-0.97)$ & 0.0314 \\
\hline No, n (\%) & $3873(98.45)$ & 7709 (97.98) & 1.00 & & 1.00 & \\
\hline
\end{tabular}

Data are presented as $\mathrm{n}$ (\%). Conditional logistical regression was used. Adjusted by DM, HTN, CHF, stroke, cancer, and liver disease. ESRD end-stage renal disease, $H D$ hemodialysis, $O R$ odds ratio, $A O R$ adjusted odds ratio

Table 4 Comparison of the risk of delayed intracranial hemorrhage after head injury between the Case $\left(H^{+E S R D}\right)$ and Control $\left(H D^{-E S R D}\right)$ groups

\begin{tabular}{|c|c|c|c|c|c|c|}
\hline Outcome & Case & Control & Crude OR & $P$ & AOR & $P$ \\
\hline \multicolumn{7}{|l|}{ Overall } \\
\hline Yes, n (\%) & 78 (1.12) & $108(0.78)$ & $1.46(1.09-1.96)$ & 0.0124 & $1.35(0.97-1.88)$ & 0.0737 \\
\hline No, n (\%) & 6860 (98.88) & $13,768(99.22)$ & 1.00 & & 1.00 & \\
\hline \multicolumn{7}{|l|}{ Gender } \\
\hline \multicolumn{7}{|l|}{ Male } \\
\hline Yes, n (\%) & $37(1.22)$ & $52(0.86)$ & $1.43(0.94-2.19)$ & 0.0990 & $1.41(0.86-2.29)$ & 0.1706 \\
\hline No, n (\%) & 3003 (98.78) & 6028 (99.14) & 1.00 & & 1.00 & \\
\hline \multicolumn{7}{|l|}{ Female } \\
\hline Yes, n (\%) & $41(1.05)$ & $56(0.72)$ & $1.48(0.98-2.24)$ & 0.0595 & $1.28(0.81-2.02)$ & 0.2950 \\
\hline No, n (\%) & 3857 (98.95) & 7740 (99.28) & 1.00 & & 1.00 & \\
\hline \multicolumn{7}{|l|}{ Age (years) } \\
\hline \multicolumn{7}{|l|}{$0<65$} \\
\hline Yes, n (\%) & $38(1.26)$ & $41(0.68)$ & $1.89(1.21-2.96)$ & 0.0055 & $1.46(0.78-2.73)$ & 0.2353 \\
\hline No, n (\%) & 2966 (98.74) & 5967 (99.32) & 1.00 & & 1.00 & \\
\hline \multicolumn{7}{|l|}{$\geq 65$} \\
\hline Yes, n (\%) & $40(1.02)$ & $67(0.85)$ & $1.20(0.81-1.78)$ & 0.3703 & $1.16(0.77-1.76)$ & 0.4829 \\
\hline No, n (\%) & 3894 (99.98) & 7801 (99.15) & 1.00 & & 1.00 & \\
\hline
\end{tabular}


the threshold of head CT in $\mathrm{HD}^{+\mathrm{ESRD}}$ patients after HI. In the $\mathrm{HD}^{+\mathrm{ESRD}}$ elderly, a subgroup more sensitive to $\mathrm{ICH}$, the criteria for head CT need not be different from those of the general population. This evidence should be valuable for establishing future guidelines for managing $\mathrm{HI}$ and may reduce medical costs by reducing the number of head CTs done, especially in the elderly.

Heparin has a short half-life of about one hour [14], which might be the most important reason that the risk for ICH does not rise after HI. One meta-analysis [15] suggests that using heparin use during dialysis does not significantly increase the risk of bleeding. Another study [16] reported that access-related bleeding was the most common in patients on HD [16]. Major bleeding related to heparin such as brain, gastrointestinal tract, and pericardium are uncommon, except for patient-specific reasons [16]. Heparin is commonly administered as a bolus injection before dialysis begins, and is then continuously infused during the dialysis treatment [17]. Before the end of dialysis, heparin infusions are typically stopped for approximately $30 \mathrm{~min}$ [16]. This procedure permits prompt hemostasis after the access needles have been removed [16]. It also protects patients from being exposed to a bleeding risk after HD.

There are no published studies about ICH after $\mathrm{HI}$ in $\mathrm{HD}^{+\mathrm{ESRD}}$ patients. However, the published studies about the risk of non-traumatic ICH in HD patients have controversial results. In one Japanese study [18], HTN and the amount of HD prescribed were the risk factors, but anticoagulation with heparin was not. A study based on the US Renal Data System [19] showed that the occurrence rate of non-traumatic subdural hematoma in long-term HD patients is 10 times higher than that of the general population. The author concluded that it may be related to a greater use of anticoagulants in long-term HD patients; however, the study focused only on subdural hematoma and did not include patients with other types of $\mathrm{ICH}$, such as subarachnoid, intracerebral, and epidural hemorrhages. In addition, it enrolled patients with traumatic and with non-traumatic $\mathrm{ICH}$, which is different from our goal for traumatic ICH.

Bleeding is also a great concern in HD patients who need surgery. However, studies on this topic are also inconsistent. In two studies [20,21], there was no greater incidence of bleeding in dialysis patients undergoing a vitrectomy for diabetic retinopathy. In a study about non-cardiac surgeries [22], HD patients had a risk for postoperative bleeding 1.4 times higher than that of non-HD patients. Although there are no randomized prospective studies, it is unlikely that individuals whose ESRD is well managed with HD would have a greater risk for clinically significant bleeding, even from multiple dental extractions.
Our study showed that the incidence of ICH in elderly $\mathrm{HD}^{+\mathrm{ESRD}}$ patients was no higher than in elderly $\mathrm{HD}$ -ESRD patients. Age is a risk factor for $\mathrm{ICH}$, even in mild HI. In the Canadian CT Head Rule [11] and New Orleans Criteria [10], the elderly have a greater risk of clinically significant lesions that require acute neurosurgical intervention or prolonged inpatient observation $[23,24]$. Early CT scanning, where it is available, is strongly indicated $[23,24]$.

Our study showed that $\mathrm{HD}^{+\mathrm{ESRD}}$ patients had more comorbidities but a lower risk of immediate ICH after $\mathrm{HI}$ than did $\mathrm{HD}^{-\mathrm{ESRD}}$ patients. Immediate $\mathrm{ICH}$ after $\mathrm{HI}$ always comes from a more severe trauma mechanism $[25,26] . \mathrm{HD}^{+\mathrm{ESRD}}$ patients are more sedentary than $\mathrm{HD}^{-\mathrm{ESRD}}$ patients due to lowered hemoglobin level, lower extremity muscle strength, and poor physical functioning [27]. Therefore, more sedentary life style may contribute to a lower risk of immediate $\mathrm{ICH}$ after $\mathrm{HI}$ in $\mathrm{HD}^{+\mathrm{ESRD}}$ patients.

There are several limitations to this study. First, there was no information on the severity of $\mathrm{ICH}$ or $\mathrm{HI}$; therefore, we were unable evaluate the severity association between them. Second, some important drugs such as warfarin and aspirin were not investigated; therefore, we were unable to adjust for these variables as contributing factors in this study. Third, some HD ${ }^{+E S R D}$ patients used heparin-free protocol during HD. However, the proportion was small [28] and might not affect the final result of this large-scale study. Finally, despite our database being national, our findings may not be generalizable to other nations.

\section{Conclusions}

This is the first nationwide population-based study to clarify that $\mathrm{HD}^{+\mathrm{ESRD}}$ patients have no greater risk of $\mathrm{ICH}$ after $\mathrm{HI}$ than do $\mathrm{HD}^{-\mathrm{ESRD}}$ patients, regardless of age. In the immediate $\mathrm{ICH}$ analysis, $\mathrm{HD}^{+\mathrm{ESRD}}$ patients showed a lower risk than did HD ${ }^{-E S R D}$ patients. Therefore, it may not necessary for physicians to lower the threshold of head CT in $\mathrm{HD}^{+\mathrm{ESRD}}$ patients after HI.

\section{Competing interest}

No potential conflicts of interest relevant to this article were reported.

\section{Authors' contributions}

HHC, CC Huang, and JHC collected, analyzed, and interpreted the data and drafted the manuscript. SFW extracted the data from the NHI databases, did the statistical analyses, and revised the manuscript. CC Hsu, HJL, JJW, HRG, and SBS provided clinical experience and revised the manuscript. CC Huang and $J H C$ conceived the study, participated in the design, supervised the conduct of the study, and helped draft the manuscript. All authors read and approved the final manuscript.

\section{Acknowledgments}

This study was supported by grants CMFHR10433 from the Chi-Mei Medical Center. This study is based in part on data from the Taiwan National Health Insurance Research Database provided by the National Health Insurance Administration, Ministry of Health and Welfare, and managed by the National 
Health Research Institutes (Registered number NHIRD-100-057, NHIRD-102024). The interpretation and conclusions contained herein do not represent those of the National Health Insurance Administration, Ministry of Health and Welfare, or National Health Research Institutes. We thank Bill Franke for his editorial assistance and invaluable advice. Bill Franke is self-employed.

\section{Author details}

${ }^{1}$ Department of Emergency Medicine, Chi-Mei Medical Center, 901

Zhonghua Road, Yongkang District, Tainan City 710, Taiwan. ${ }^{2}$ Department of Biotechnology, Southern Taiwan University of Science and Technology, Tainan, Taiwan. ${ }^{3}$ Department of Healthcare Administration and Medical Informatics, Kaohsiung Medical University, Kaohsiung, Taiwan. ${ }^{4}$ Department of Emergency Medicine, Taipei Medical University, Taipei, Taiwan.

${ }^{5}$ Department of Medical Research, Chi-Mei Medical Center, Tainan, Taiwan. ${ }^{6}$ Department of Environmental and Occupational Health, College of Medicine, National Cheng Kung University, Tainan, Taiwan. 'Department of Occupational and Environmental Medicine, National Cheng Kung University Hospital, Tainan, Taiwan. ${ }^{8}$ Department of Occupational Medicine, Chi-Mei Medical Center, Tainan, Taiwan. ${ }^{9}$ Department of Leisure, Recreation and Tourism Management, Southern Taiwan University of Science and Technology, Tainan, Taiwan. ${ }^{10}$ Department of Medical Research, Chi Mei Medical Center, Liouying, Tainan, Taiwan. ${ }^{11}$ Department of Child Care and Education, Southern Taiwan University of Science and Technology, Tainan, Taiwan. ${ }^{12}$ Department of Geriatrics and Gerontology, Chi-Mei Medical Center, Tainan, Taiwan. ${ }^{13}$ Department of Emergency Medicine, Cathay General Hospital, No. 280, Sec. 4, Ren'ai Road, Da'an District, Taipei City 106, Taiwan.

${ }^{14} \mathrm{Fu}$ Jen Catholic University School of Medicine, Taipei, Taiwan.

Received: 13 April 2015 Accepted: 23 October 2015

Published online: 28 October 2015

\section{References}

1. Collins AJ, Foley RN, Chavers B, Gilbertson D, Herzog C, Johansen K, et al. United States Renal Data System 2011 Annual Data Report: Atlas of chronic kidney disease \& end-stage renal disease in the United States. Am J Kidney Dis. 2012;59(1 Suppl 1):A7. e1-e420.

2. Kuo HW, Tsai SS, Tiao MM, Yang CY. Epidemiological features of CKD in Taiwan. Am J Kidney Dis. 2007:49:46-55.

3. U.S. Renal Data System. USRDS 2005 Annual Data Report: Atlas of End-Stage Renal Disease in the United States, National Institutes of Health. Bethesda, MD: National Institute of Diabetes and Digestive and Kidney Diseases; 2005.

4. Khan F, Baguley IJ, Cameron ID. 4: Rehabilitation after traumatic brain injury. Med J Aust. 2003;178:290-5.

5. Maas Al, Stocchetti N, Bullock R. Moderate and severe traumatic brain injury in adults. Lancet Neurol. 2008;7:728-41.

6. Langlois JA, Sattin RW. Traumatic brain injury in the United States: research and programs of the Centers for Disease Control and Prevention (CDC). J Head Trauma Rehabil. 2005:20:187-8.

7. Tagliaferri F, Compagnone C, Korsic M, Servadei F, Kraus J. A systematic review of brain injury epidemiology in Europe. Acta Neurochir (Wien). 2006;148:255-68.

8. Roozenbeek B, Maas Al, Menon DK. Changing patterns in the epidemiology of traumatic brain injury. Nat Rev Neurol. 2013;9:231-6.

9. Jagoda AS, Bazarian JJ, Bruns Jr JJ, Cantrill SV, Gean AD, Howard PK, et al. Clinical policy: neuroimaging and decisionmaking in adult mild brain injury in the acute setting. Ann Emerg Med. 2008;52:714-48.

10. Haydel MJ, Preston CA, Mills TJ, Luber S, Blaudeau E, DeBlieux PM. Indications for computed tomography in patients with minor HI. N Engl J Med. 2000;343:100-5.

11. Stiell IG, Laupacis A, Wells GA, Canadian CT Head and Cervical-Spine Study Group. Indications for computed tomography after minor head injury. Canadian CT Head and Cervical-Spine Study Group. N Engl J Med. 2000;343:1570-1

12. Cheng TM. Taiwan's national health insurance system: high value for the dollar. In: Okma KG, Crivelli L, editors. Six Countries, Six Reform Models-the Healthcare Reform Experience of Israel, the Netherlands, New Zealand, Singapore, Switzerland and Taiwan. Hackensack, NJ: World Scientific; 2009. p. 171-204.

13. Huang CC, Chung MH, Weng SF, Chien CC, Lin SJ, Lin HJ, et al. Long-term prognosis of patients with carbon monoxide poisoning: a nationwide cohort study. PLoS ONE. 2014;9:e105503.
14. Nelson DL, Cox MM. Lehninger Pinciples of Biochemistry. Fourthth ed. New York: W. H. Freeman (Macmillan Education); 2004. p. 1100.

15. Lim W, Cook DJ, Crowther MA. Safety and efficacy of low molecular weight heparins for hemodialysis in patients with end-stage renal failure: a meta-analysis of randomized trials. J Am Soc Nephrol. 2004;15:3192-206.

16. Sonawane S, Kasbekar N, Berns JS. The safety of heparins in end-stage renal disease. Semin Dial. 2006;19:305-10.

17. Ouseph R, Ward RA. Anticoagulation for intermittent hemodialysis. Semin Dial. 2000;13:181-7.

18. Kawamura M, Fijimoto S, Hisanaga S, Yamamoto Y, Eto T. Incidence, outcome, and risk factors of cerebrovascular events in patients undergoing maintenance hemodialysis. Am J Kidney Dis. 1998;31:991-6.

19. Sood P, Sinson GP, Cohen EP. Subdural hematomas in chronic dialysis patients: significant and increasing. Clin J Am Soc Nephrol. 2007;2:956-9.

20. Hayashi H, Kurata Y, Imanaga Y, Goya K, Oshima K. Vitrectomy for diabetic retinopathy in patients undergoing hemodialysis for associated end-stage renal failure. Retina. 1998;18:156-9.

21. Nawrocki J, Chrzanowski W, Koch D, Dziegielewski K. Vitreoretinal surgery in diabetic patients on hemodialysis. Eur J Ophthalmol. 1997;7:283-7.

22. Cherng YG, Liao CC, Chen TH, Xiao D, Wu CH, Chen TL. Are non-cardiac surgeries safe for dialysis patients? - A population-based retrospective cohort study. PLoS ONE. 2013;8:e58942.

23. Papa L, Stiell IG, Clement CM, Pawlowicz A, Wolfram A, Braga C, et al. Performance of the Canadian CT Head Rule and the New Orleans Criteria for predicting any traumatic intracranial injury on computed tomography in a United States Level I trauma center. Acad Emerg Med. 2012;19:2-10.

24. Wolf $\mathrm{H}$, Machold W, Frantal S, Kecht M, Pajenda G, Leitgeb J, et al. Risk factors indicating the need for cranial $C T$ scans in elderly patients with head trauma: an Austrian trial and comparison with the Canadian CT Head Rule. J Neurosurg. 2014;120:447-52.

25. Nishijima DK, Offerman SR, Ballard DW, Vinson DR, Chettipally UK, Rauchwerger AS, et al. Immediate and delayed traumatic intracranial hemorrhage in patients with head trauma and preinjury warfarin or clopidogrel use. Ann Emerg Med. 2012;59:460-8. e1-7.

26. Liao JC, Ho CH, Liang FW, Wang JJ, Lin KC, Chio CC, et al. One-year mortality associations in hemodialysis patients after traumatic brain injury-an eight-year population-based study. PLoS ONE. 2014:9:e93956.

27. Gomes EP, Reboredo MM, Carvalho EV, Teixeira DR, Carvalho LF, Filho GF, et al. Physical activity in hemodialysis patients measured by triaxial accelerometer. Biomed Res Int. 2015;2015:645645.

28. Shen Jl, Mitani AA, Chang TI, Winkelmayer WC. Use and safety of heparin-free maintenance hemodialysis in the USA. Nephrol Dial Transplant. 2013;28:1589-602.

\section{Submit your next manuscript to BioMed Central and take full advantage of:}

- Convenient online submission

- Thorough peer review

- No space constraints or color figure charges

- Immediate publication on acceptance

- Inclusion in PubMed, CAS, Scopus and Google Scholar

- Research which is freely available for redistribution 